\title{
Effect of Post Growth Annealing on the Structural and Electrical Properties of $\mathrm{ZnO} / \mathrm{CuO}$ Composite Nanostructures
}

\author{
Mushtaque Hussain*, Azam Khan, Omer Nur and Magnus Willander \\ Department of Science and Technology, Campus Norrköping, Linköping University, \\ SE-60174 Norrköping, Sweden
}

(Received December 13, 2013)

\begin{abstract}
In the present work, $\mathrm{ZnO} / \mathrm{CuO}$ composite nanostructures have been grown on fluorine doped tin oxide coated glass substrate by aqueous chemical growth method. To observe the effect of post growth annealing $\left(500^{\circ} \mathrm{C}, 1 \mathrm{~min}\right)$ on the structural properties of $\mathrm{ZnO}$ nanorods scanning electron microscope and X-ray diffraction techniques have been utilized. SEM images of post growth annealed (post growth annealed) sample reveal that the average diameter of $\mathrm{ZnO}$ NRs has considerably increased in comparison with as grown sample. Moreover after post growth annealing the $\mathrm{ZnO}$ NRs showed more clearly hexagonal wurtzite structure. Beside this the NRs are also uniform and well aligned with a high aspect ratio of $\sim 10$. In XRD pattern the strongly intense (002) peak of the post growth annealing sample suggest that the crystal quality of the NRs have also been improved significantly. Since the structural improvement have a significant impact on charge transport properties as well, therefore the effect of post growth annealed has also been investigated by the electrical characterization of $\mathrm{ZnO} / \mathrm{CuO}$ based heterojunction. The current-voltage measurements of the post growth annealed sample showed improvement in the current in comparison with as grown sample. The impedance study has also confirmed that the post growth annealed has influence on the electrical properties. The presented post growth annealed heterojunction of $\mathrm{ZnO} / \mathrm{CuO}$ may have space in applications like sensors and oxide based diodes in the devices fabrication.

DOI: 10.12693 /APhysPolA.126.849
\end{abstract}

PACS: $81.40 . \mathrm{Rs}, 81.40 .-\mathrm{z}$

\section{Introduction}

Research on nanostructures (NSs) of different materials and their use in device fabrication has been rapidly increasing with the passage of time, as the unique properties of NSs have proven to be more suitable in comparison to the bulk phase of similar materials. As the NSs have large surface area to volume ratio which renders surface defects. This property is very useful for many applications like sensors. Many materials have been utilized by researchers for the synthesis of different NSs. Among those zinc oxide $(\mathrm{ZnO})$ as an $n$-type metal oxide compound semiconductor, having a direct wide band gap $(3.37 \mathrm{eV})$ and relatively large exciton binding energy $(60 \mathrm{meV})$ has attracted the attention of many researchers. The reason is the diverse and unique properties of $\mathrm{ZnO}$ such as electro-optical, piezoelectric, and magnetic [1-3]. $\mathrm{ZnO}$ has also been used for the applications such as optoelectronic, chemical and bio sensing [4-6]. Beside these features, $\mathrm{ZnO}$ exhibits the diverse family of morphologies in comparison with any other metal oxide material. To prepare different $\mathrm{ZnO}$ NSs there are many synthetic routes both at low and high temperatures $[7,8]$. The relatively low temperature $\left(<100^{\circ} \mathrm{C}\right)$ aqueous chemical growth (ACG) method has been considered more favorable for the synthesis of variety of $\mathrm{ZnO}$ NSs with excellent properties. This method enables the production of nanodevices on soft substrates, such as paper, cotton textile fabric and the flexible plastic substrate [9-11].

Since reproducible and high quality $p$-type $\mathrm{ZnO}$ is still difficult to achieve, therefore fabrication of an effective

*corresponding author; e-mail: mushtaque.hussain@liu.se
$\mathrm{ZnO} p-n$ homojunction remained challenging. So $\mathrm{ZnO}$ based hetero-junctions can be used as an alternative with a suitable $p$-type material. In this regard cupric oxide $(\mathrm{CuO})$ is an important $p$-type compound semiconductor having a narrow band gap $(1.35 \mathrm{eV})$, that has been widely investigated due to its high theoretical capacity, high safety, environmental benignity and low cost [1215]. $\mathrm{CuO}$ has great potential for various applications such as a field emitter, catalyst and as a gas sensing medium [16-18]. Various methods have been employed for the fabrication of $\mathrm{CuO}$ NSs [8, 19-21]. However, the $\mathrm{CuO} \mathrm{NSs}$ grown through thermal oxidation process or synthesized through wet chemical routes demonstrated poor adhesion to substrates like glass [22]. Therefore selection of synthesis method is also very important. Both $\mathrm{ZnO}$ and $\mathrm{CuO}$ NSs have been investigated many times in recent past by using different techniques such as chemical vapor deposition, hydrothermal methods and some solution based processes, but simple and low cost ACG method utilizing bottom up approach has proven to be successful for the synthesis of $\mathrm{ZnO}$ or $\mathrm{CuO}$ NSs with high yield on the substrate [23]. However, relatively fewer studies on the $\mathrm{CuO} / \mathrm{ZnO}$ or $\mathrm{ZnO} / \mathrm{CuO}$ composite NSs have been reported as yet [23-25]. To fabricate these desired composite NSs, several preparation methods have been applied by researchers [24, 26-28]. Among these, hexamethylenetetramine assisted ACG method $[6,8]$ is relatively simple, inexpensive, surfactant-free and can be carried out at low temperatures $\left(<100^{\circ} \mathrm{C}\right)$.

It was observed by many researchers that temperature has an influence on the structural and electrical properties of nanostructured materials. Mandal et al. reported that transport properties of NSs are different as compared to the bulk phase [29]. The electrical properties 
of nanostructured materials are generally influenced by the high surface-to-volume ratio of grains, small size, enhanced contribution from grains and grain boundaries, quantum confinement of charge carriers, band structure modification and defects in grains [30]. $\mathrm{ZnO}$ thin films were synthesized by rf magnetron sputtering associated with the rapid thermal annealing in the environment of nitrogen or oxygen ambient, and the obtained information demonstrated that rapid thermal annealing at high temperature has significant effect on the compressive stress and crystal quality [31]. To the best of our knowledge, studies concerning the influence of post growth annealed (PGA) $\left(500^{\circ} \mathrm{C}, 1 \mathrm{~min}\right)$ process of $\mathrm{ZnO} / \mathrm{CuO}$ heterojunction prepared by using ACG method are still lacking. Also the influence of PGA on the electrical properties of $\mathrm{ZnO} \mathrm{NSs}$ and the heterojunction based on $\mathrm{ZnO}$ is not completely explored as yet. Hence the deeper insight of PGA on the electrical behavior is still very important for $\mathrm{ZnO}$ based heterojunctions because of their large impact on their practical applications.

In this research work, a heterojunction of $\mathrm{ZnO} / \mathrm{CuO}$ has been developed on fluorine doped tin oxide (FTO) coated glass substrate by ACG method. At the same time, $\mathrm{PGA}$ was performed at $500^{\circ} \mathrm{C}$ for $1 \mathrm{~min}$ and the influence of PGA on the structural and electrical properties of the fabricated heterojunction is investigated. The structural study was performed by employing scanning electron microscope (SEM) and X-ray diffraction (XRD) techniques and the electrical study by typical I-V characteristics along with impedance spectroscopy.

\section{Experimental}

\subsection{Growth of $\mathrm{ZnO} / \mathrm{CuO}$ composite nanostructures}

The following chemicals were purchased from SigmaAldrich, Sweden and used without any further purification. Hexamethylenetetramine $\left[\mathrm{C}_{6} \mathrm{H}_{12} \mathrm{~N}_{4}\right]$, zinc nitrate hexahydrate $\left[\mathrm{Zn}\left(\mathrm{NO}_{3}\right)_{2} \cdot 6 \mathrm{H}_{2} \mathrm{O}\right]$, copper nitrate pent hydrate $\left[\mathrm{Cu}\left(\mathrm{NO}_{3}\right)_{2} \cdot 5 \mathrm{H}_{2} \mathrm{O}\right]$, copper acetate monohydrate $\left[\mathrm{Cu}\left(\mathrm{CH}_{3} \mathrm{COO}\right)_{2}\right]$ and FTO coated glass substrate.

The synthesis of $n$-type $\mathrm{ZnO} / p$-type $\mathrm{CuO}$, NSs based heterojunction was performed in two steps by using ACG method. In first step the method was employed for the growth of $\mathrm{CuO}$ NSs on FTO coated glass substrates. First of all the substrates were sonicated in ultrasonic bath for $20 \mathrm{~min}$ in isopropanol, then washed with the deionized water and dried by flow of nitrogen gas. A copper acetate monohydrate seed crystal solution was deposited on these substrates in order to act as the nucleation site for $\mathrm{CuO}$ NSs by using spin-coating technique. This procedure was repeated twice at $3000 \mathrm{rpm}$ for $20 \mathrm{~s}$ each time and after that the samples were annealed at $120^{\circ} \mathrm{C}$ for $20 \mathrm{~min}$ in order to have good adhesion of seed particles. After annealing, the FTO coated glass substrates decorated with $\mathrm{CuO}$ particles were placed in a beaker containing equi-molar solution of $0.025 \mathrm{M}$ hexamethylenetetramine and copper nitrate penthydrate by the help of a Teflon sample holder. The $\mathrm{pH}$ of the growth solution was 6.5-7. Afterwards, the samples contained beaker was kept in preheated electric oven at $80^{\circ} \mathrm{C}$ for
4-5 hours. After the growth duration the samples with the $\mathrm{CuO}$ NSs were washed with deionized water in order to remove residual solid particles from the surface. Finally, the samples were dried in air at room temperature. After the fabrication of $\mathrm{CuO} \mathrm{NSs}$, the growth of $\mathrm{ZnO} \mathrm{NRs}$ on top of $\mathrm{CuO} \mathrm{NSs}$ was carried out. CuO NSs were used as the $p$-type contact as well as the substrate for the growth of $\mathrm{ZnO}$ NRs in the present study.

A seed solution of zinc acetate dihydrate was spin coated on the $\mathrm{CuO}$ NSs grown on FTO coated glass substrate. The spin coating process was repeated twice at $3000 \mathrm{rpm}$ for $20 \mathrm{~s}$ each time and after that the samples were annealed at $120^{\circ} \mathrm{C}$ for $20 \mathrm{~min}$. An equimolar concentration $(0.075 \mathrm{M})$ solution of zinc nitrate hexahydrate and hexamethylenetetramine was prepared in 60 $\mathrm{ml}$ of deionized water. Then the substrates were dipped into the solution facing downward by using Teflon sample holder and were kept in a pre-heated electric oven at $95^{\circ} \mathrm{C}$ for 5-6 h. After the completion of growth time the substrates were cleaned with the de-ionized water and dried at room temperature. To study the effect of PGA on electrical properties of $\mathrm{ZnO} / \mathrm{CuO}$ heterojunction, PGA at $500^{\circ} \mathrm{C}$ was employed for 1 minute by using hot plate.

\subsection{Fabrication of $n-\mathrm{ZnO} / \mathrm{p}-\mathrm{CuO} p-n$ junction}

For device fabrication an insulating polymer (Shipley photoresist S-1805) was applied at 4000 r.p.m on the grown $\mathrm{ZnO} / \mathrm{CuO}$ composite NSs and then placed at hotplate at a temperature of $120^{\circ} \mathrm{C}$ for approximately one minute in order to get dried/good adhesion of the photoresist. Reactive ion etching (RIE) plasma was used for exposing the top surfaces of the $\mathrm{ZnO} / \mathrm{CuO}$ composite NSs. In order to develop the electrodes on exposed top of the $\mathrm{ZnO} / \mathrm{CuO}$ composite NSs a plastic shadow mask having circles of $1 \mathrm{~mm}$ in diameter was used. A silver layer of $50 \mathrm{~nm}$ thickness was deposited by using SATIS evaporator (thermal evaporation at a pressure of $2 \times 10^{-7}$ Torr) for developing these electrodes. The schematic diagram in Fig. 1 is showing the fabrication process of $\mathrm{ZnO} / \mathrm{CuO}$ based heterojunction.

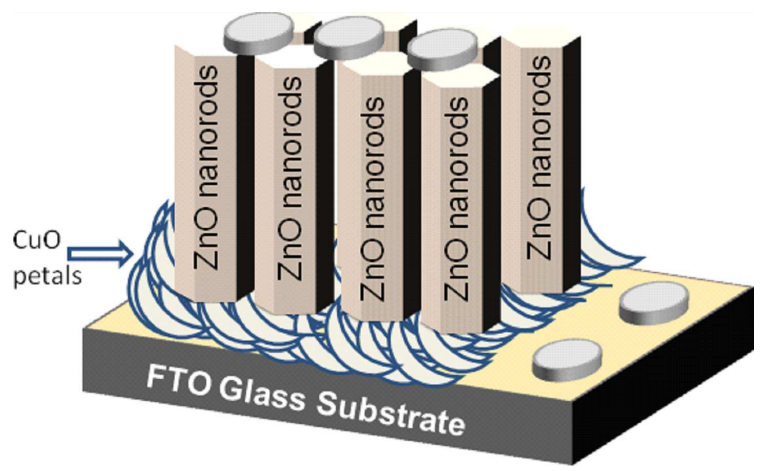

Fig. 1. Schematic diagram showing the fabrication process of $\mathrm{ZnO} / \mathrm{CuO}$ based device.

The morphology and structural properties of nanofabricated $n-\mathrm{ZnO} / p-\mathrm{CuO}$ heterojunction was studied by using LEO 1550 Gemini field emission scanning electron 
microscope running (FESEM) at $15 \mathrm{kV}$. The crystal quality of $n-\mathrm{ZnO} / p-\mathrm{CuO}$ composite NSs was studied by Xray powder diffraction (XRD) using a Phillips PW 1729 powder diffractometer equipped with $\mathrm{Cu} K_{\alpha}$ radiation $(\lambda=1.5418 \AA)$ using a generator voltage of $40 \mathrm{kV}$ and a current of $40 \mathrm{~mA}$. The electrical characterization was performed by using parameter analyzer and impedance spectrometer to show the rectifying behavior of the proposed $\mathrm{ZnO} / \mathrm{CuO}$ heterojunction.

\section{Results and discussion}

\subsection{Structural characterizations}

The surface and cross section morphology of the grown $n-\mathrm{ZnO} / p$-CuO composite NSs was analysed by SEM. The SEM image of as grown $\mathrm{CuO}$ NSs is shown in Fig. 2a. The leaves like $\mathrm{CuO}$ NSs have petals with a length, width and thickness of $\sim 500 \mathrm{~nm}, \sim 200-250 \mathrm{~nm}$ and $\sim 50 \mathrm{~nm}$, respectively. The $\mathrm{ZnO}$ NRs were grown on the leaf like morphology of $\mathrm{CuO}$ NSs and the obtained $\mathrm{ZnO}$ NRs were almost uniformly distributed over the substrate. In addition to this NRs are well aligned and perpendicular to the substrate as well. Figure $2 \mathrm{~b}$ is a cross sectional SEM image of the $\mathrm{ZnO}$ NRs over the leaves like $\mathrm{CuO}$ NSs. For clear understanding the layer of $\mathrm{CuO}$ leaves has been pointed out using parallel lines. The SEM image in Fig. $2 \mathrm{c}$ shows the high density of grown $\mathrm{ZnO}$ NRs on the top of $\mathrm{CuO}$ NSs. The NRs are rather uniform with a diameter of $\sim 80 \mathrm{~nm}$. Figure $2 \mathrm{~d}$ is the SEM image of $\mathrm{ZnO} / \mathrm{CuO}$ composite NSs after receiving the PGA of $500{ }^{\circ} \mathrm{C}$ for 1 min. It can be seen from SEM image in the Fig. $2 d$ that PGA has not only affect the diameter of as grown $\mathrm{ZnO}$ NRs, which is now around $\sim 130 \mathrm{~nm}$, but it also released the strain within the NRs that resulted in more excellent hexagonal structure as compared to as grown NRs. Ultimately these well uniform and a bit larger $\mathrm{ZnO}$ NRs combined with larger grains will cause a reduction in the defect centres between the grain boundaries as reported by Yen et al. [32]. He further pointed out that this reduction may be attributed to the relaxation of bonding in order to fill the defect vacancies. Beside this Fan et al. [33] reported that short thermal annealing can elevate the non polar crystal planes containing ZnO NRs due to the reduction of surface energy.

In order to examine the crystal quality and to confirm the PGA effect on crystal structure of $\mathrm{ZnO}$ NRs, the XRD analysis has been carried out. Figure 3 is showing the typical XRD scan $\left(0.1^{\circ} / \mathrm{s}\right)$ in the $2 \theta$ range $\left(25^{\circ}-65^{\circ}\right)$. Figure 3a is showing the XRD spectra of the bare $\mathrm{CuO}$ petal like NSs. The diffraction peaks (002), (111), (112) and $(1,1,-3)$ denoted by stars are related to $\mathrm{CuO}$ as per JCPDS card no. 05-0661. whereas Fig. 3b-c is showing the XRD spectra of the as grown and PGA $\left(500{ }^{\circ} \mathrm{C}\right.$ for 1 min) $n-\mathrm{ZnO} / p-\mathrm{CuO}$ composite NSs, respectively. All the diffraction peaks (100), (002), (101), (102), (103) and (110) of $\mathrm{ZnO}$ are consistent according to JCPDS card no. 36-1451. The highest diffraction peak (002) of PGA sample in Fig. 3c showed as much as 10 times high intensity in comparison with as grown sample in Fig. 3b. In addition to this it is clear from Fig. 3 that the intensity

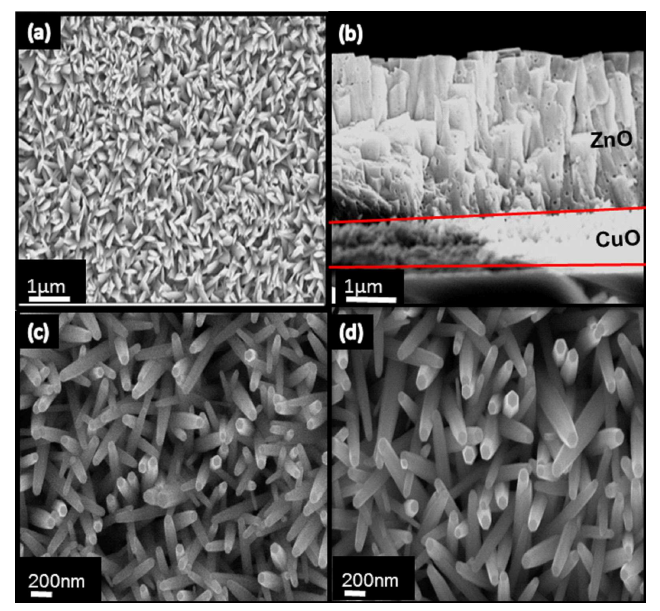

Fig. 2. (a) The SEM image of bare CuO NSs, (b) cross sectional SEM image of $\mathrm{ZnO} / \mathrm{CuO}$ composite NSs, (c) the top view SEM image of as grown $\mathrm{ZnO} / \mathrm{CuO}$ composite NSs, (d) the top view SEM image of PGA $\mathrm{ZnO} / \mathrm{CuO}$ composite NSs.

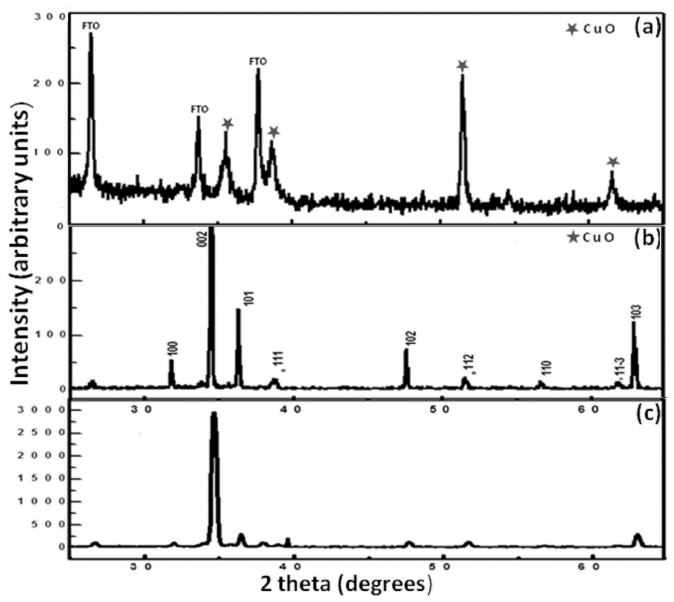

Fig. 3. XRD spectra of $\mathrm{ZnO} / \mathrm{CuO}$ composite NSs. (a) As grown (b) PGA at $500{ }^{\circ} \mathrm{C}$ for $1 \mathrm{~min}$.

ratio of (002) to (101) diffraction peaks is much higher in PGA sample in comparison with as grown sample. This confirms that PGA has enhanced the preferential orientation in the $c$-axis direction. By employing the Bragg law and the Scherrer formula, we find out the lattice parameters, spacing and the size of the as grown and PGA samples with respect to (002) crystal plane as given in Table. No other impurities were found in the prepared samples.

TABLE

Representation of the lattice parameters, spacing and the dimensions calculated at (002) plane.

\begin{tabular}{l|c|c|c|c|c}
\hline \hline Sample & $a(\AA)$ & $c(\AA)$ & $d(\AA)$ & FWHM & Thickness $(\AA)$ \\
\hline As grown & 3.2 & 5.2 & 2.6 & 0.06 & 1541.8 \\
PGA $\left(500{ }^{\circ} \mathrm{C}\right)$ & 3.2 & 5.2 & 2.6 & 0.38 & 243.4
\end{tabular}


It was observed that the PGA has affected the structural parameters, so it was interesting to see its impact on charge transport properties as well. Because the enlarged crystal size of $\mathrm{ZnO}$ NRs will not only facilitate the electron movement but also modify the localized states like bulk and surface trap sites.

\subsection{Electrical characterization}

For the detailed investigation of the electrical transport properties, $I-V$ characteristics and impedance measurements were done at room temperature. The results of $I-V$ characteristics of $\mathrm{ZnO} / \mathrm{CuO}$ composite NSs (as grown and PGA samples) are presented in linear scale. It can be seen in Fig. 4a that both curves are showing well defined rectifying diode like behaviour, beside this PGA sample curve showed improvement in the current in comparison with as grown sample suggesting significant decrement in the resistance of PGA sample.
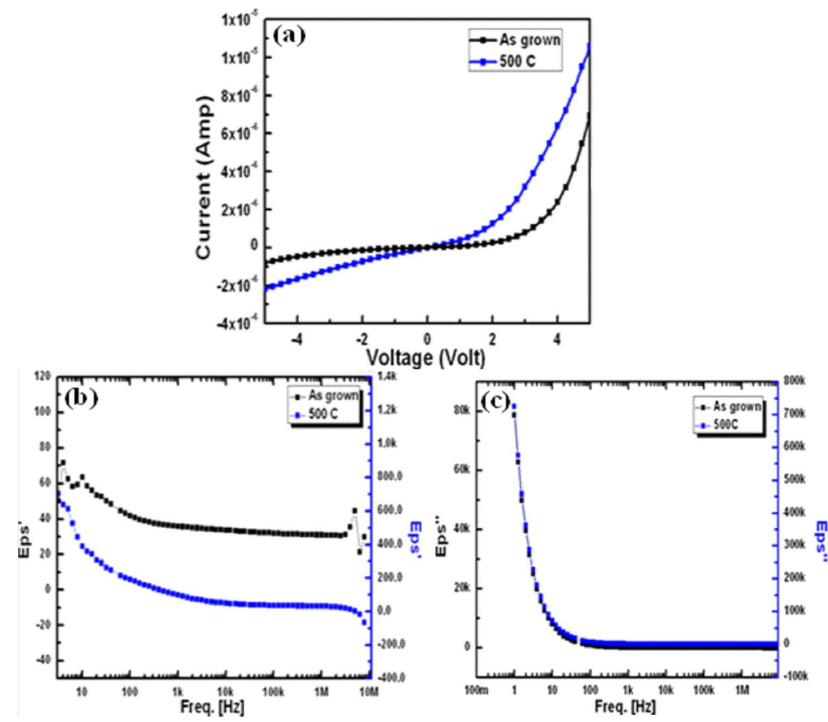

Fig. 4. (a) Typical $I-V$ Characteristics of $\mathrm{ZnO} / \mathrm{CuO}$ composite NSs of as grown and PGA $\left(500{ }^{\circ} \mathrm{C}\right.$ for 1 minute) samples showing the effect of PGA. Dielectric behavior for as grown and PGA $\left(500{ }^{\circ} \mathrm{C}\right.$ for $\left.1 \mathrm{~min}\right)$ samples of $\mathrm{ZnO} / \mathrm{CuO}$ based device (a) dielectric constant, (b) dielectric loss

To the best of our knowledge there is no single study available, which addresses the effect of post growth annealing $\left(500{ }^{\circ} \mathrm{C}\right.$ for 1 minute) on the morphology of $\mathrm{ZnO} / \mathrm{CuO}$ composite NSs by using impedance spectroscopy. Impedance spectroscopy has been widely used by the researchers to analyze the charge transport behavior of nanocrystalline materials. This analysis also provides a correlation between the electrical and structural properties of the material. Beside this the effect of temperature and frequency on the dielectric behavior and impedance spectra of $\mathrm{ZnO}$ NRs has also been utilized to study different polarization mechanisms, grain and grain boundary effect in nanostructured materials.

The frequency dependent behaviour of dielectric constant $\left(\varepsilon^{\prime}\right)$ and dielectric loss $\left(\varepsilon^{\prime \prime}\right)$ of $\mathrm{ZnO} / \mathrm{CuO}$ composite
NSs (as grown and PGA samples) observed at room temperature in the frequency range of $1 \mathrm{~Hz}$ to $10 \mathrm{MHz}$ are shown in Fig. 4b and c. In Fig. 4b different slopes over three frequency regions have been detected. The samples showed strong frequency dispersion at low frequency $(<300 \mathrm{~Hz})$. It can be seen that that $\varepsilon^{\prime}$ decreases with increasing frequency due to the existence of different polarization mechanisms in the sample. The decrease of dielectric constant with increasing frequency $(<10 \mathrm{kHz})$ is attributed to the existence of space charge polarization in the NR and above that frequency the dominant mechanism is the orientation polarization. The $\mathrm{ZnO}$ NRs exhibit space charge polarization due to their structural inhomogeneities such as vacancies and micropores at the grain boundaries. Their surface defects cause a change of positive and negative space charge distributions at the interface, which resulted in a much higher dielectric constant value of PGA sample than as grown sample at low frequencies as indicated in Fig. 4b. In Fig. 4c the behavior of as grown and PGA sample is almost identical, initially $\varepsilon^{\prime \prime}$ decreased rapidly with increase in frequency but as frequency approached around $200 \mathrm{~Hz}$ then $\varepsilon^{\prime \prime}$ attains a constant value. This can be explained on the basis of different polarization mechanisms existing in the samples. Under an applied external field the space charges move and are trapped by defects at the interfaces, creating many dipole moments. At low frequencies $(<10 \mathrm{kHz})$, hopping electrons are trapped by the structural inhomogeneities. Therefore at low frequencies the space charge polarization becomes strongly dominant (almost 10 times) in PGA sample than as grown sample. Above $10 \mathrm{kHz}$, due to rotational displacement of dipoles in the NRs the dominant polarization mechanism is orientation polarization. The existence of oxygen vacancies and zinc interstitials in the NR is the possible source of orientation polarization. At higher frequencies, the space charges cannot follow the change of the field and hence do not produce space charge polarization. The dipoles are also unable to follow rapidly with varying electric field. Therefore Fig. 4c reveals a clear variation in the magnitude of dielectric loss for both samples with respect to frequency that illustrates the typical dispersion behavior for polarizations in the relaxation regime.

The complex impedance spectroscopy is an important tool to analyze the electrical properties of the device. The electrical behavior of the diodes (as grown and PGA) were studied over a range of frequency using the complex impedance spectroscopy (CIS). This technique enables us to separate the real and imaginary components of the electrical parameters and hence provides a true picture of the material properties.

Figure 5 shows the complex impedance spectroscopy of $\mathrm{ZnO} / \mathrm{CuO}$ composite NSs grown on FTO coated glass substrate. Figure 5a shows the variation in the real part of impedance $Z_{s}^{\prime}$ as a function of frequency for both samples. It is clear that the magnitude of $Z_{s}^{\prime}$ decreases with increasing frequency. The high value at low frequencies is due to the total polarization caused by space charge, 


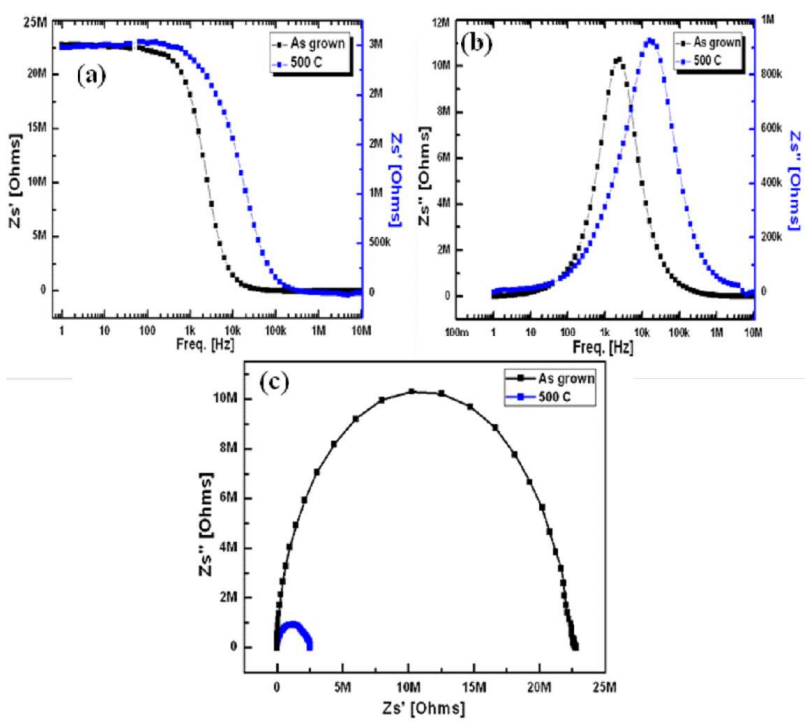

Fig. 5. Frequency dependent impedance for as grown and PGA $\left(500^{\circ} \mathrm{C}\right.$ for $\left.1 \mathrm{~min}\right)$ samples of $\mathrm{ZnO} / \mathrm{CuO}$ based device, (a) real part, (b) imaginary part, (c) Cole- Cole plot.

dipoles, ions and electrons [34]. Figure 5b shows the variation of the imaginary part of impedance $Z_{s}^{\prime \prime}$ with respect to frequency for as grown as well as PGA sample. It is clear that the values of $Z_{s}^{\prime \prime}$ increased with increasing frequency, until it reached to a maximum peak $Z_{s}^{\prime \prime}$ and then is decreased with the further increase in frequency. A significant broadening along with shift in the peak position appeared in the PGA sample that suggests the existence of a temperature-dependent electrical relaxation phenomenon in the heterojunction. In Fig. $5 \mathrm{c}$ the impedance measurement of $\mathrm{ZnO} / \mathrm{CuO}$ reveals two overlapped arcs of semicircles. The broader one belongs to as grown sample while the much smaller one is for PGA sample. Figure 5c clearly shows the substantial drop in the grain resistance of the PGA sample suggesting that the bulk resistance has decreased incredibly in comparison with as grown sample. Because on injection of charge carriers the barrier height reduced, this enhanced the electrical conduction of PGA sample. It is also possible that the decrease in the resistance of PGA sample caused due to the increase in thermal movement of the defects, especially the oxygen vacancies [35].

\section{Conclusion}

$\mathrm{ZnO} / \mathrm{CuO}$ composite NSs were grown by lowtemperature ACG method on FTO coated glass substrate with PGA at $500{ }^{\circ} \mathrm{C}$ for $1 \mathrm{~min}$. The effect of PGA on the $\mathrm{ZnO}$ NRs was investigated by SEM and XRD. It has been observed that PGA promotes densification of the $\mathrm{ZnO}$ nanocrystallites and surface area reduction. The $\mathrm{ZnO}$ NRs after PGA have more clearly hexagonal structure and the diameter has also been increased considerably. The strongly enhanced (002) peak in PGA sample and a high aspect ratio confirmed the improvement in the preferential orientation along the c-axis. Moreover the effect of PGA was also observed through electrical characterization. The diode behavior was examined through I-V and an improvement in the current of PGA sample was observed due to possible reduction in resistance, which caused a better rectifying behavior in comparison with as grown sample. In impedance measurements a substantial drop in the grain resistance of the PGA sample was observed. These results showed that the PGA improved the crystalline quality besides affecting the electrical properties. The present study indicates that the PGA has favorable influence in combination with ACG method for the fabrication of optoelectronic $\mathrm{ZnO}$ NRs arrays that have potential applications in sensors and the devices based on solid state oxide junction.

\section{References}

[1] S. Ilican, M. Caglar, Y. Caglar, Appl. Surf. Sci. 256, 7204 (2010).

[2] Z.L. Wang, J.H. Song, Science 312, 242 (2006).

[3] K. Ando, H. Saito, Z.W. Jin, T. Fukumura, M. Kawasaki, Y. Matsumoto, H. Koinuma, J. Appl. Phys. 89, 7284 (2001).

[4] R. Ghosh, S. Fujihara, D. Basak, J. Electr. Mater. 35, 1728 (2006).

[5] J.Y. Park, D.E. Song, S.S. Kim, Nanotechnology 19, 105503 (2008).

[6] M.H. Asif, A. Fulati, O. Nur, M. Willander, C. Brannmark, P. Stralfors, S.I. Borjesson, F. Elinder, Appl. Phys. Lett. 95, 023703 (2009).

[7] Z.L. Wang, J. Phys.: Cond. Matter. 16, R829 (2004).

[8] A. Zainelabdin, S. Zaman, G. Amin, O. Nur, M. Willander, Cryst. Growth. Des. 10, 3250 (2010).

[9] M.Y. Soomro, I. Hussain, N. Bano, O. Nur, M. Willander, Phys. Status. Solidi R 6, 80 (2012).

[10] A. Khan, M.A. Abbasi, M. Hussain, Z.H. Ibupoto, J. Wissting, O. Nur, M. Willander, Appl. Phys. Lett. 101, 193506 (2012).

[11] M. Willander, O. Nur, S. Zaman, A. Zainelabdin, N. Bano, I. Hussain, J. Phys. D: Appl. Phys. 44, 224017 (2011).

[12] M. Willander, O. Nur, G. Amin, A. Zainelabdin, S. Zaman, MRS Proc. 1406, (2011).

[13] J. Morales, L. Sanchez, F. Martin, J.R. RamosBarrado, M. Sanchez, Electrochem. Acta 49, 4589 (2004).

[14] S.Y. Gao, S.X. Yang, J. Shu, S.X. Zhang, Z.D. Li, K. Jiang, J. Phys. Chem. C 112, 19324 (2008).

[15] X.J. Zhang, D.G. Zhang, X.M. Ni, J.M. Song, H.G. Zheng, J. Nanopart. Res. 10, 839 (2008).

[16] Y.W. Zhu, T. Yu, F.C. Cheong, X.J. Xu, C.T. Lim, V.B.C. Tan, J.T.L. Thong, C.H. Sow, Nanotechnology 16, 88 (2005).

[17] F. Teng, W. Yao, Y. Zheng, Y. Ma, Y. Teng, T. Xu, S. Liang, Y. Zhu, Sens. Act. B: Chem. 134, 761 (2008).

[18] X.Y. Xue, L.L. Xing, Y.J. Chen, S.L. Shi, Y.G. Wang, T.H. Wang, J. Phys. Chem. C. 112, 12157 (2008).

[19] J. Morales, L. Sanchez, F. Martin, J.R. RamosBarrado, M. Sanchez, Thin Solid Films 474, 133 (2005). 
[20] X. Fei, Z.Z. Shao, X. Chen, Nanoscale 5, 7991 (2013).

[21] M. Xu, F. Wang, B. Ding, X. Song, J. Fang, RSC Advances 2, 2240 (2012).

[22] D. Li, Y.H. Leung, A.B. Djurisic, Z.T. Liu, M.H. Xie, J. Gao, W.K. Chan, J. Cryst. Growth 282, 105 (2005).

[23] A. Zainelabdin, S. Zaman, G. Amin, O. Nur, M. Willander, Appl. Phys. A 108, 921 (2012).

[24] A. Zainelabdin, G. Amin, S. Zaman, O. Nur, J. Lu, L. Hultman, M. Willander, J. Mater. Chem. 22 11583 (2012)

[25] M. Willander, K.ul. Hassan, O. Nur, A. Zainelabdin, S. Zaman, G. Amin, J. Mater. Chem. 22, 2337 (2012).

[26] Y. Zhu, C.H. Sow, T. Yu, Q. Zhao, P. Li, Z. Shen, D. Yu, J.T. Thong, Adv. Funct. Mater. 16, 2415 (2006).

[27] P. Wang, X. Zhao, B. Li, Opt. Expr. 19, 11271 (2011)
[28] S. Jung, S. Jeon, K. Yong, Nanotechnology 22, 015606 (2011).

[29] S. Mandal, K. Sambasivarao, A. Dhar, S.K. Ray, AIP 106, 024103 (2009).

[30] V. Biju, M. Abdul Khaddar, J. Mater. Sci. 36, 5779 (2001).

[31] Y.C. Lee, S.Y. Hu, W. Water, Y. Huang, M. Yang, T. Shen, K. Tiong, C. Huang, Solid State Commun. 143, 250 (2007).

[32] T. Yen, D. Strome, S.J. Kim, A.N. Cartwright, W.A. Anderson, J. Electron. Mater. 37, 764 (2008).

[33] D. Fan, R. Zhang, X. Wang, Physica E: Low-dimens. Syst. Nanostr. 42, 2081 (2010).

[34] S.K. Jaiswal, J. Kumar, J. Alloys Comp. 509, 3859 (2011).

[35] M. Dawber, J.F. Scotta, A.J. Hartmann, J. Eur. Ceram. Soc. 21, 1633 (2001). 